\title{
Deuterium retention in tungsten exposed to low-energy and high-flux "clean"' and carbon-seeded deuterium plasmas
}

\author{
V.Kh. Alimov ${ }^{1}$, J. Roth ${ }^{2}$, R.A. Causey ${ }^{3}$, D.A. Komarov ${ }^{1}$, Ch. Linsmeier ${ }^{2}$, A. Wiltner ${ }^{2}$, \\ F. Kost ${ }^{2}$, S. Lindig ${ }^{2}$ \\ ${ }^{1}$ Institute of Physical Chemistry and Electrochemistry, Russian Academy of Sciences, \\ Leninsky prospect 31, 119991 Moscow, Russia \\ ${ }^{2}$ Max-Planck-Institut für Plasmaphysik, EURATOM Association, \\ Boltzmannstrasse 2, D-85748 Garching, Germany \\ ${ }^{3}$ Sandia National Laboratories, P.O. Box 969, Livermore, CA 94550, USA
}

\section{Introduction}

Tungsten and carbon fibre composites (CFC) are the candidate materials in the divertor region in ITER where the armors will be subjected to high flux $\left(10^{22} \mathrm{~m}^{-2} \mathrm{~s}^{-1}\right.$ or higher $)$ deuterium-tritium plasmas [1]. Because of high sputtering yield and chemical erosion of the CFC materials, the sputtered carbon particles and hydrocarbon species can migrate into the plasma. They will be ionized by the energetic electrons and, together with hydrogen isotope ions, implanted into tungsten. Carbon and hydrocarbon impurities in the hydrogen plasma will not only govern the process of tungsten erosion and carbon deposition as reported in Ref. [2-8], but will create near-surface layers of tungsten carbides, $\mathrm{W}_{2} \mathrm{C}$ and WC, depending on the conditions like the supply of thermal energy or particle bombardment [9-13], and also affect the surface deformation such as blistering [11, 14-16].

Despite of the fact that a great deal of publications was devoted to the hydrogen isotope retention in $\mathrm{W}$ materials [17-45], the influence of the carbon impurities in a hydrogen (deuterium, tritium) plasma or ion beam on the hydrogen isotope retention in $\mathrm{W}$ materials has not been examined yet. There are only indications that the vacuum conditions during D ion irradiation could influence deuterium retention in single crystal tungsten: a higher level of background impurities leads to a higher D retention [32, 43].

Studies of carbon re-deposition on polycrystalline tungsten in a controlled carboncontaminated deuterium plasma environment were performed in the linear magnetized

\footnotetext{
${ }^{1}$ We use the term "clean" in quotation marks having in mind the impossibility to obtain absolutely clean plasma. In our case the conception "clean" D plasma means the plasma without intentionally introduced carbon impurities.
} 
plasma facility PISCES-B [23]. Tungsten substrates were exposed to a high ion flux $\left(10^{22}\right.$ $\left.\mathrm{m}^{-2} \mathrm{~s}^{-1}\right)$ and low energy $(\leq 100 \mathrm{eV} / \mathrm{D})$ deuterium plasma for a total fluence of the order of $10^{26} \mathrm{D} / \mathrm{m}^{2}$. Downstream $\mathrm{CD}_{4}$ puffing was used to produce carbon impurities in the deuterium plasma at various substrate temperatures. At an impurity level of about $1 \% \mathrm{CD}_{4}$, no carbon deposition was observed on the plasma-exposed substrates at temperatures below $700 \mathrm{~K}$. While the substrate temperature increased to $850 \mathrm{~K}$, carbon particles started to form on the tungsten surface. Deuterium retention measurements were done using thermal desorption spectrometry. The dominant factors influencing the hydrogen isotope retention in plasma exposed tungsten were the substrate temperature, $T_{\exp }$, and whether carbon was deposited on the tungsten surface. For uncontaminated tungsten surfaces the total isotope retention at $T_{\exp } \leq 500 \mathrm{~K}$ was in the range from about $5 \times 10^{20}$ to about $5 \times 10^{21}$ $\mathrm{D} / \mathrm{m}^{2}$. These values were about one order of the magnitude higher than those after exposure at higher temperatures $(>700 \mathrm{~K})$. The deposited carbon increased the retention of deuterium which was mainly residing within the carbon film.

The retention of deuterium implanted at room temperature in pure and pre-irradiated with $40 \mathrm{keV} \mathrm{C}$ ions W single crystals was studied by Alimov et al. [46]. D ion implantation was performed at energies of $10 \mathrm{keV}$ with the range confined in the carbon-modified layer and of $100 \mathrm{keV}$ with the range exceeding the carbon-modified layer. The carbon preimplantation influences the deuterium retention only if the range of the $\mathrm{D}$ ions is confined within the carbon-modified surface layer. In this case deuterium diffusion beyond the ion range does not occur and the retained amount of deuterium is smaller than in the pure $\mathrm{W}$ crystal. At a D ion energy where the deuterium range exceeds the carbon-modified layer the deuterium retention is the same for carbon-implanted and pure $\mathrm{W}$ samples.

For polycrystalline tungsten pre-irradiated with $1 \mathrm{keV} \mathrm{C}$ ions and subsequently implanted with $500 \mathrm{eV}$ D ions, Poon et al. [47] observed that deuterium retention in carbon-implanted W strongly dependeds on the $\mathrm{C}$ ion fluence and the implantation temperature. With a low $\mathrm{C}$ ion fluence, tungsten carbide WC was formed at the surface, leading to a decreased $\mathrm{D}$ retention at low $\mathrm{D}$ ion fluence, compared to the pure $\mathrm{W}$ case. With a high carbon ion fluence and low D ion fluence, the presence of a graphitic surface layer increases the $\mathrm{D}$ retention above the pure $\mathrm{W}$ case. With increasing $\mathrm{D}$ ion fluence, preferential sputtering removes both the graphitic surface layer and the implanted $\mathrm{C}$ from the bulk, such that the D retention behaviour of the specimen tends towards that of pure $\mathrm{W}$ (with no carbon ion pre-implantation) at high D ion fluences.

The purpose of this work consists in studying deuterium retention in monocrystalline and polycrystalline tungsten exposed to "clean" and carbon-seeded D plasmas at exposure 
temperatures in the range from 313 to $853 \mathrm{~K}$. Information about the total amount of deuterium retained in the $\mathrm{W}$ materials is obtained from thermal desorption measurements. Moreover, measurements of deuterium depth profiles can give detailed information about the fractions of deuterium retained both in the near-surface layers and in the bulk of the investigated materials. Therefore, the impact of carbon surface impurities on the D retention in the bulk of the plasma-exposed tungsten can be revealed. In our study the $\mathrm{D}\left({ }^{3} \mathrm{He}, \mathrm{p}\right){ }^{4} \mathrm{He}$ nuclear reaction at different ${ }^{3} \mathrm{He}$ energies was used for quantitative depth profiling.

\section{Experimental}

Two types of $\mathrm{W}$ materials were investigated:

(i) Single crystal tungsten specimens produced by double electron-beam zone melting. The manufacturer, the State Institute of Rare Metals (Moscow), quoted the purity as about 99.9 at.\% with the main impurities being $\mathrm{H}(0.02$ at.\%), $\mathrm{C}(0.05$ at.\%) and $\mathrm{O}(0.05$ at.\%). The macro-crystallite sizes were in the range of 10-20 $\mathrm{mm}$. The specimens were cut from a $\mathrm{W}$ rod by spark cutting and were $0.8-0.9 \mathrm{~mm}$ in thickness. The sample surface was parallel to the (100) crystallographic plane.

(ii) A hot-rolled polycrystalline tungsten foil (powder-metallurgy product, 99 at.\% W, 0.03 at. $\% \mathrm{H}, 0.1$ at.\% C, 0.2 at.\% O, 0.1 at.\% N, 0.5 at.\% other impurities - Fe, Al, Si, $\mathrm{Ni}, \mathrm{Mg}$ ) has been investigated. The grain sizes were 1-5 $\mu \mathrm{m}$. The samples were cut from the $0.5 \mathrm{~mm}$ thick foil by spark cutting.

The single-crystalline and polycrystalline $\mathrm{W}$ samples, $6 \times 8 \mathrm{~mm}^{2}$ in size, were mechanically and electrochemically polished.

The W samples were exposed to "clean" and carbon-seeded deuterium plasmas at various exposure temperatures $T_{\exp }$ in the range from 313 to $853 \mathrm{~K}$ at Institute of Physical Chemistry and Electrochemistry, Russian Academy of Sciences, Moscow (IPCE).

The "clean" plasma was generated in a planar dc magnetron operated with $\mathrm{D}_{2}$ gas at a pressure of about $1 \mathrm{~Pa}$. The samples placed on the cathode surface and covered with a tantalum mask with an aperture of $5 \mathrm{~mm}$ in diameter were bombarded with plasma ions accelerated in the cathode sheath of the magnetron discharge with a discharge voltage of $450 \mathrm{~V}$. The spatial distribution of the plasma potential showed that the cathode-drop voltage was about 0.85 of the discharge voltage. Reasoning that $\mathrm{D}_{2}{ }^{+}$ions dominate in the plasma, the mean energy of $\mathrm{D}$ ions was estimated to be about $200 \mathrm{eV}$. The ion flux was determined from ion current measurements and was $1.1 \times 10^{21} \mathrm{D} /\left(\mathrm{m}^{2} \mathrm{~s}\right)$. 
The carbon-seeded D plasmas were generated by placing plates of pyrolytic graphite within the sputter-dominated area of the cathode surface at distance of about $8 \mathrm{~cm}$ from the W sample. The plasma generated by using one graphite plate of about $7.5 \mathrm{~cm}^{2}$ in surface area is denoted as " $\mathrm{D}+\mathrm{C}(\mathrm{I})$ " plasma. The plasma generated by using two graphite plates with total surface area of about $15 \mathrm{~cm}^{2}$ is denoted as " $\mathrm{D}+\mathrm{C}(\mathrm{II})$ ". Only polycrystalline W samples were exposed to the carbon-seeded D plasmas.

The W samples were exposed to the "clean" and carbon-seeded D plasmas for 30 min resulting in an ion fluence of $2 \times 10^{24} \mathrm{D} / \mathrm{m}^{2}$. During plasma exposure the sample temperature was measured by a chromel-alumel thermocouple welded to the front surface of the sample outside the irradiation area.

The deuterium profiles were determined by nuclear reaction analysis (NRA) at MaxPlanck-Institut für Plasmaphysik, Garching (IPP). The D concentration within the nearsurface layer (at depths up to about $0.5 \mu \mathrm{m}$ ) was measured by means of the $\mathrm{D}\left({ }^{3} \mathrm{He}, \alpha\right) \mathrm{H}$ reaction at a ${ }^{3} \mathrm{He}$ energy of $0.69 \mathrm{MeV}$, and the $\alpha$ particles were energy-analyzed with a small-angle surface barrier detector with a solid angle of $9.17 \mathrm{msr}$ at the laboratory scattering angle of $102^{\circ}$. The $\alpha$ spectrum was transformed into a D depth profile using the program SIMRNA [48]. To determine the D concentration at larger depths, an analyzing beam of ${ }^{3} \mathrm{He}$ ions with energies varied from 0.69 to $4.0 \mathrm{MeV}$ was used. The protons from the $\mathrm{D}\left({ }^{3} \mathrm{He}, \mathrm{p}\right){ }^{4} \mathrm{He}$ nuclear reaction were counted using a wide-angle proton detector with a solid angle of $0.15 \mathrm{sr}$ placed at a scattered angle of $135^{\circ}$. The $\mathrm{D}\left({ }^{3} \mathrm{He}, \mathrm{p}\right)^{4} \mathrm{He}$ nuclear reaction has a broad maximum at around $0.63 \mathrm{MeV}$ which can be used for resonant depth profiling. In order to determine the $\mathrm{D}$ concentration profile in deeper layers, the computer program SIMNRA was used for the deconvolution of the proton yields measured at different ${ }^{3} \mathrm{He}$ ion energies. A deuterium depth distribution was assumed taking into account the nearsurface depth profile obtained from the $\alpha$ particle spectrum, and the proton yield as a function of incident ${ }^{3} \mathrm{He}$ energy was calculated. The form of the $\mathrm{D}$ depth profile was then varied using an iterative technique until the calculated curve matched the measured proton yields [49].

The impurity concentration and chemical state in the outermost atomic layers on the tungsten surface was determined at IPP by X-ray photoelectron spectroscopy (XPS) which probes core-level transitions giving information on the specific element including its chemical environment (Table 1). All photoelectron spectra were measured using a monochromatic Al $K_{\alpha}$ source $\left(E_{K_{\alpha}}=1486.6 \mathrm{eV}\right)$. For survey spectra a pass energy of 93.9 eV was used. To achieve the highest energy resolution, the hemispherical energy 
analyzer was driven at $2.95 \mathrm{eV}$ pass energy yielding an energy resolution of $0.3 \mathrm{eV}$. The binding energy was calibrated with the $\mathrm{Au} 4 \mathrm{f}_{7 / 2}$ peak at $84.0 \mathrm{eV}$ and $\mathrm{Cu} 2 \mathrm{p}$ and $\mathrm{Ag} 3 \mathrm{~d}$ peaks for linearity. Depth profiles were acquired by sputtering with a scanned $3 \mathrm{keV}$ Ar ion beam. The sputtered area was about $2 \times 2 \mathrm{~mm}^{2}$, and ion beam current on the target was about $0.4 \mu \mathrm{A}$.

To determine the binding energies and different fractions of binding states in the high-resolution XPS spectra, curve-fitting procedures were carried out using the MultiPak software package [51]. For the non-linear least-squares optimization procedure, a Gaussian-Lorentzian line shape was used and a Shirley background was applied [52].

Table 1. Binding energies for $\mathrm{C}$ 1s in carbon films and tungsten carbides [50] (preliminary data were published in [9])

\begin{tabular}{lc} 
Substance & Binding energy for C 1s [eV] \\
\hdashline Graphitic carbon & 284.2 \\
Disordered graphitic carbon & 285.1 \\
$\mathrm{~W}_{2} \mathrm{C}$ & 283.4 \\
$\mathrm{WC}$ & 282.9
\end{tabular}

The surface morphology of the plasma-exposed $\mathrm{W}$ samples was investigated by scanning electron microscope (SEM).

\section{Results}

\subsection{Deuterium depth profiles}

The retention of deuterium in tungsten develops differently at different depths. The depth at which deuterium is retained in the $\mathrm{W}$ materials irradiated with low-energy $\mathrm{D}$ ions or exposed to a D plasma is divided into three zones: (i) the near-surface layer (up to a depth of 0.2-0.5 $\mu \mathrm{m}$, depending on the ion energy), (ii) a sub-surface layer (from about 0.5 to about $3 \mu \mathrm{m}$ ), and (iii) the bulk (>6 $6 \mathrm{~m})$ [39].

In the single-crystalline and polycrystalline $\mathrm{W}$ materials exposed to the "clean" lowenergy $(\approx 200 \mathrm{eV} / \mathrm{D})$ and high-flux (about $1 \times 10^{21} \mathrm{D} / \mathrm{m}^{2} \mathrm{~s}$ ) magnetron $\mathrm{D}$ plasma at exposure 
temperatures of $T_{\exp }=303-313 \mathrm{~K}$, the D depth profiles are characterized by a sharp nearsurface concentration maximum of about 1 at. $\%$ and a decreasing concentration tail into the bulk (Fig. 1). At $T_{\exp }=413-493 \mathrm{~K}$, the D profiles demonstrate, in addition to the nearsurface peak, a relatively high D concentration (0.3-0.4 at.\%) in the sub-surface layer. The main difference between single-crystalline and polycrystalline $\mathrm{W}$ materials is the constant concentration level in the bulk for polycrystalline material which is absent in single crystals.

The concentration of $\mathrm{D}_{2}$ molecules (in arbitrary units) within the near-surface layer of the $\mathrm{W}$ crystal was determined by measuring $\mathrm{D}_{2}$ release rate in the course of surface sputtering with Ar ions (residual gas analysis, RGA, by quadrupole mass spectrometer). A characteristic of the $\mathrm{D}_{2}$ release rate after exposure to the "clean" D plasma at $T_{\exp }=373 \mathrm{~K}$ is that repetitive $\mathrm{D}_{2}$ gas bursts occur throughout the whole analysis time corresponding to a depth of $\sim 450 \mathrm{~nm}$ (Fig. 2). The appearance of $\mathrm{D}_{2}$ molecules is related to the formation of voids filled by gaseous deuterium. Based on the D depth profiles (Fig. 1), one may assume the void formation at depths at least up to $1-2 \mu \mathrm{m}$.

In the $\mathrm{W}$ single crystal exposed to the "clean" D plasma, the deuterium retention is about $1 \times 10^{20} \mathrm{D} / \mathrm{m}^{2}$ at $T_{\exp }=303 \mathrm{~K}$ and, as exposure temperature further increases, rises to its maximum of about $4 \times 10^{20} \mathrm{D} / \mathrm{m}^{2}$ at $T_{\exp }=463 \mathrm{~K}$ and then decreases down to about $2 \times 10^{19} \mathrm{D} / \mathrm{m}^{2}$ at $T_{\exp }=533 \mathrm{~K}$ (Fig. $3 \mathrm{a}$ ). In the polycrystalline $\mathrm{W}$ exposed to the "clean" D plasma, the $\mathrm{D}$ retention demonstrates practically the same temperature dependence as that in the $\mathrm{W}$ single crystal, but the maximum retention in the polycrystalline $\mathrm{W}$ is about $5 \times 10^{20}$ $\mathrm{D} / \mathrm{m}^{2}$ at $T_{\exp }=493 \mathrm{~K}$ (Fig. $3 \mathrm{a}$ ). Both in single-crystalline and polycrystalline $\mathrm{W}$ exposed to the "clean" D plasma at $T_{\exp }=303-313 \mathrm{~K}$, the retention in the near-surface (at depths from 0 to $0.3 \mu \mathrm{m}$ ) is higher than that in the sub-surface layer and in the bulk (at depths from 0.3 to $7 \mu \mathrm{m}$ ), whereas at $T_{\text {exp }}$ above $350 \mathrm{~K}$ the $\mathrm{D}$ retention at depths above $0.3 \mu \mathrm{m}$ starts to be dominating and reaches about $90 \%$ of the total D retention at $T_{\exp }=450-500 \mathrm{~K}$ (Fig. 4).

In the polycrystalline $\mathrm{W}$ irradiated with $200 \mathrm{eV} \mathrm{D}$ ions at low flux (about $4 \times 10^{19}$ $\left.\mathrm{D} / \mathrm{m}^{2} \mathrm{~s}\right)$, the $\mathrm{D}$ retention decreases drastically as the irradiation temperature increases from 323 to $393 \mathrm{~K}$ (Fig. 3 a). The D retention with a maximum at higher temperature is observed when the $\mathrm{W}$ materials are exposed to high flux D plasma. Data on the D retention in polycrystalline $\mathrm{W}$ exposed to low-energy (about $100 \mathrm{eV} / \mathrm{D}$ ) and high flux (about $1 \times 10^{22}$ $\mathrm{m}^{-2} \mathrm{~s}^{-1}$ ) hydrogen isotope plasmas taken from Refs. [21, 27, 42, 45] are shown in Fig. $3 \mathrm{~b}$. As seen from the figure, for the ion fluxes of about $1 \times 10^{22} \mathrm{~m}^{-2} \mathrm{~s}^{-1}$ a drastic decrease in the $\mathrm{D}$ retention is observed at the exposure temperatures above $650-700 \mathrm{~K}$. In our experiments 
with the ion flux of about $1 \times 10^{21} \mathrm{~m}^{-2} \mathrm{~s}^{-1}$, the decrease in the $\mathrm{D}$ retention begins at about $500 \mathrm{~K}$. Evidently, the ion flux affects not only the D retention in W materials, as it was reported in $[27,32]$, but also the temperature where the $\mathrm{D}$ retention reaches its maximum.

The D depth profiles in the polycrystalline $\mathrm{W}$ exposed to the carbon-seeded D plasmas ("D+C(I)" and "D+C(II)" plasmas) (Fig. 5) at first sight are similar to those measured after "clean" D plasma exposure (Fig. 1). However, after exposure to carbon seeded plasmas the near-surface concentration maximum is about 3 at.\% (compare with about 1 at.\% for the "clean" D plasma exposure), and the exposure temperature when the D profiles demonstrate a maximum $\mathrm{D}$ concentration at depths of 2-3 $\mu \mathrm{m}$ is higher than that for the "clean" D plasma exposure. It is significant that in the W samples exposed to the carbon-seeded D plasmas at temperatures above $600 \mathrm{~K}$, the D concentration in the bulk (at depths beyond $6 \mu \mathrm{m}$ ) is about one order of magnitude higher than that after exposure to the “clean” D plasma (compare Figs. 1 and 5).

After exposure to carbon-seeded D plasmas, the maximum D retention is observed at the exposure temperatures of $603 \mathrm{~K}$ ("D+C(I)" plasma) and $563 \mathrm{~K}$ ("D+C(II)" plasma), whereas for "clean" D plasma exposure the maximum retention is at $T_{\exp }=493 \mathrm{~K}$ (Fig. 4). Generally, maximum D retention after exposure to carbon seeded plasmas at elevated temperatures is $(5-9) \times 10^{20} \mathrm{D} / \mathrm{m}^{2}$ and is comparable to the maximum retention after exposure to a "clean" D plasma.

The temperature dependences of the D content in the near-surface layer (at depths from 0 to $0.3 \mu \mathrm{m}$ ) for exposure to the "clean" and carbon-seeded D plasmas are different (Fig. 4 a). If for the "clean" D plasma exposure the D content is about $5 \times 10^{19} \mathrm{D} / \mathrm{m}^{2}$ at $T_{\exp }$ $=313 \mathrm{~K}$ and starts to fall drastically at the exposure temperature of about $500 \mathrm{~K}$, that for the carbon-seeded D plasma exposure the D content in the near-surface layer is $1 \times 10^{20}$ $\mathrm{D} / \mathrm{m}^{2}$ at low exposure temperatures and starts to decrease slowly at the exposure temperature of about $600 \mathrm{~K}$. As evident from XPS spectra (see paragraph 3.3), for the carbon-seeded plasmas the degree of covering of the $\mathrm{W}$ surface with an amorphous deuterated carbon film is higher then that for the "clean" D plasma.

As for the "clean" D plasma exposure, the D content at depths from 0.3 to $7 \mu \mathrm{m}$ in polycrystalline exposed to carbon-seeded D plasmas $T_{\exp }=400-700 \mathrm{~K}$ is higher that that in the near-surface W layer (Fig. 4 b).

\subsection{Formation of blisters}


SEM micrographs of the single-crystalline W exposed to the "clean" D plasma and micrographs of the polycrystalline W exposed to the "clean" and carbon-seeded D plasmas to an ion fluence of $2 \times 10^{24} \mathrm{D} / \mathrm{m}^{2}$ at various exposure temperatures are shown in Figs. 6-8. Dome-shaped elevations named blisters are formed on the metal surface exposed to the D plasmas at elevated temperatures. The shapes of most blisters are almost spherical with sizes ranging from about 2 to $50 \mu \mathrm{m}$, depending on the $\mathrm{W}$ structure and conditions of the $\mathrm{D}$ plasma exposure.

After exposure to the "clean" D plasma at $T_{\exp }=303 \mathrm{~K}$, the blisters are not formed on the surface of the single-crystalline W sample. However, after exposure at temperatures in the range from 373 to $533 \mathrm{~K}$ blisters appear on the surface of the $\mathrm{W}$ crystals, and the size (diameter) of blisters is 1-5 $\mu \mathrm{m}$ (Fig. 6). The maximum areal density of blisters is observed at $T_{\exp }=413-463 \mathrm{~K}$, whereas at $T_{\exp }=533 \mathrm{~K}$ only solitary blisters are present on the surface (Fig. 6 b).

For the polycrystalline W exposed both to the "clean" D plasma at $T_{\exp }=418-493 \mathrm{~K}$ and to the carbon-seeded D plasma at $T_{\exp }=463-603 \mathrm{~K}$, cracks are observed on the surface of blister lids (Fig. 7 b). Note that after exposure to the $\mathrm{D}$ plasmas at these temperatures the $\mathrm{D}$ depth profiles demonstrate the concentration minimum between the near-surface and bulk maxima (Figs. $1 \mathrm{~b}$ and 5). The maximum areal density of blisters is observed at $T_{\exp }=$ $493 \mathrm{~K}$ for the "clean" D plasma and at $T_{\exp }=533-603 \mathrm{~K}$ for the carbon-seeded D plasmas. At these exposure temperatures the $\mathrm{D}$ content at depths beyond $0.3 \mu \mathrm{m}$ reaches its maximum (Fig. 4 b).

The dependence of blister mean size (diameter) on the exposure temperature for the polycrystalline $\mathrm{W}$ is shown in Fig. 9. For the "clean" D plasma exposure, the mean blister size is about $3 \mu \mathrm{m}$ at $T_{\exp }=313 \mathrm{~K}$ and grows to the maximum value of about $30 \mu \mathrm{m}$ at $T_{\exp }$ $=573 \mathrm{~K}$ (Fig. 8 a). At a higher exposure temperature the blister size starts to decrease. For the carbon-seeded D plasma exposure, the blister size demonstrates the opposite temperature dependence. At $T_{\exp }=363-413 \mathrm{~K}$ the mean blister size is around $50 \mu \mathrm{m}$ and decreases to about $20 \mu \mathrm{m}$ at the exposure temperature of $563 \mathrm{~K}$ (Fig. 8 b). Further increase of the exposure temperature leads to the growth of the blisters in size. It should be noted that a tungsten carbide layer is formed on the $\mathrm{W}$ surface during exposure to the carbonseeded D plasmas and is not formed during exposure to the "clean" D plasma.

For exposure to both the "clean" and carbon-seeded D plasmas at $T_{\exp }$ above $680 \mathrm{~K}$, no blister formation is observed on all W surfaces (Fig. 9). 


\subsection{Surface composition}

The carbon, oxygen, and tungsten concentration on the surface of the polycrystalline $\mathrm{W}$ exposed to the "clean" and carbon-seeded D plasmas was determined from the survey XPS spectra (an example is shown in Fig. 10). The elemental concentrations are calculated from the survey spectra using tabulated sensitivity factors Since no elemental depth profile within the XPS information depth (several $\mathrm{nm}$ ) is available, the concentrations are calculated assuming a homogeneous distribution over this range. In the survey spectra the signals from $\mathrm{Na}, \mathrm{N}$ and $\mathrm{Cu}$ are detected in addition to the expected peaks of $\mathrm{C}, \mathrm{O}$ and $\mathrm{W}$. $\mathrm{Cu}$ is presumably sputtered from copper parts in the magnetron device and co-deposited during exposure to the D plasmas. After the plasma exposure the samples were kept in air until the XPS analysis was carried out and $\mathrm{Na}, \mathrm{N}$, and $\mathrm{C}$ impurity accumulation at the top surface could be attributed to the air exposure. The high $\mathrm{C}$ concentrations (around 50 at.\%) measured directly after sample loading (before Ar sputtering) are typically observed on samples which were carried through the air. These adsorbed layers can be easily removed by sputtering with low Ar fluences. Therefore, we took into consideration the results obtained after surface sputtering with fluences above $1 \times 10^{19} \mathrm{Ar} / \mathrm{m}^{2}$. In all cases, the remaining concentrations of the detected impurities (besides carbon and oxygen) are below 1 at.\% and are not expected to influence the deuterium inventory.

Although all samples contain carbon in the surface layer, the concentration is lowest for the samples exposed to the "clean" D plasma. The carbon concentration in the nearsurface layers in these cases does not exceed 18 at.\% (Table 2). After exposure to the carbon-seeded plasmas, however, the $\mathrm{C}$ concentration always exceeds 25 at.\%.

The chemical state of the carbon presented at the surface is determined in highresolution C 1s spectra. Disordered graphitic carbon (peak at binding energy of $285.1 \mathrm{eV}$ ) is found on the W samples exposed both to the "clean" and carbon-seeded D plasmas. Contaminations from the air usually also show peaks at higher binding energies in the $\mathrm{C} 1 \mathrm{~s}$ region (around $289 \mathrm{eV}$ ) and are not any more present after the lowest applied sputtering fluence of $1 \times 10^{19} \mathrm{Ar} / \mathrm{m}^{2}$, therefore we concluded that contaminations from the transport through the air have largely been removed by gentle Ar sputtering procedure.

For the polycrystalline W exposed to the "clean" D plasma, no indications for carbide formation are visible in the $\mathrm{C}$ 1s core-level XPS spectra measured after sputtering with $\mathrm{Ar}$ ions at fluences below $7.5 \times 10^{19} \mathrm{Ar} / \mathrm{m}^{2}$ (Fig. 11). Since Ar ion bombardment also leads to the formation of carbides already at $300 \mathrm{~K}$ [53], the absence of carbide intensity in these spectra indicates that no tungsten carbides are present in the surface after the 
exposure to the "clean" D plasma. In the spectra measured after the surface sputtering with fluences above $7.5 \times 10^{19} \mathrm{Ar} / \mathrm{m}^{2}$, small peaks at the carbide positions are detected (not shown here) and can be explained by the influence of the Ar ion beam.

For the polycrystalline $\mathrm{W}$ exposed to the carbon-seeded plasmas, however, the $\mathrm{C} 1 \mathrm{~s}$ core-level XPS spectra measured after surface sputtering with lowest Ar ion fluence $\left(1 \times 10^{19} \mathrm{Ar} / \mathrm{m}^{2}\right)$ indicate clearly peaks for tungsten subcarbide $\mathrm{W}_{2} \mathrm{C}$ (at binding energy of $283.4 \mathrm{eV}$ ) (Fig. 11). The appearance of this peak can be explained by the implantation of carbon from the carbon-seeded plasmas into the tungsten surface and the formation of carbide by the energetic $\mathrm{C}$ atoms. Assuming formation of tungsten carbide with a stoichiometry of $\mathrm{W}_{2} \mathrm{C}$ and analyzing data on the impurity concentration in the near-surface layer of polycrystalline W exposed to the "pure" and carbon-seeded D plasmas (Table 2), the coverage of $\mathrm{W}$ surface with carbide phase can be estimated to be $20-40 \%$ for the $\mathrm{D}+\mathrm{C}(\mathrm{I})$ plasma and $55-60 \%$ for the $\mathrm{D}+\mathrm{C}(\mathrm{II})$ plasma.

Table 2. The impurity concentration in the near-surface layer of polycrystalline $\mathrm{W}$ exposed to the "pure" and carbon-seeded D plasmas. The XPS measurements were carried out after surface sputtering with $3 \mathrm{keV}$ Ar ions at a fluence of $1 \times 10^{19} \mathrm{Ar} / \mathrm{m}^{2}$.

\begin{tabular}{|c|c|c|c|c|c|}
\hline $\begin{array}{l}\text { Type of plasma // } \\
\text { exposure temperature }\end{array}$ & W [at.\%] & O [at.\%] & $\begin{array}{c}\text { C (total) } \\
\text { [at.\%] }\end{array}$ & $\begin{array}{l}\mathrm{C} \text { (in carbide } \\
\text { phase) [at.\%] }\end{array}$ & $\begin{array}{c}\mathrm{C} \text { (in carbide phase) } \\
\text { to } \mathrm{W} \text { atomic ratio }\end{array}$ \\
\hline $\begin{array}{c}\text { “clean" D plasma // } \\
T_{\exp }=418 \mathrm{~K}\end{array}$ & 52.0 & 35.9 & 12.1 & 1.6 & 0.03 \\
\hline $\begin{array}{c}\text { “clean" D plasma // } \\
T_{\exp }=463 \mathrm{~K}\end{array}$ & 34.5 & 47.6 & 17.9 & 0 & 0 \\
\hline $\begin{array}{c}\text { "D+C(I)" plasma // } \\
T_{\exp }=413 \mathrm{~K}\end{array}$ & 41.8 & 32.6 & 25.6 & 8.0 & 0.19 \\
\hline $\begin{array}{c}\text { "D+C(I)" plasma // } \\
T_{\exp }=603 \mathrm{~K}\end{array}$ & 46.9 & 24.4 & 28.7 & 5.0 & 0.11 \\
\hline $\begin{array}{c}\text { "D }+\mathrm{C}(\mathrm{II}) " \text { plasma } / / \\
T_{\exp }=383 \mathrm{~K}\end{array}$ & 30.4 & 25.3 & 44.3 & 8.9 & 0.29 \\
\hline $\begin{array}{c}\text { "D }+\mathrm{C}(\mathrm{II}) \text { " plasma // } \\
T_{\exp }=563 \mathrm{~K}\end{array}$ & 37.2 & 35.2 & 27.6 & 10.2 & 0.27 \\
\hline
\end{tabular}

Oxygen atoms are present on the W surfaces both after "clean" and carboncontaminated D plasma exposures. The oxygen concentration shows no dependency on the type of the plasma. 


\section{Discussion}

The high deuterium concentration in the sub-surface layer and the formation of blisters allows the conclusion that exposure to a low-energy and high ion flux D plasma modifies the surface to depths of up to $2-4 \mu \mathrm{m}$, both for $\mathrm{W}$ single crystals and polycrystalline $\mathrm{W}$. The sputter-RGA measurements show that a part of deuterium is accumulated in the form of $\mathrm{D}_{2}$ molecules in the near-surface layer (Fig. 2). It could be supposed that $\mathrm{D}_{2}$ molecules (or rather $\mathrm{D}_{2}$-filled voids) are formed in the sub-surface layer also (up to depths of several micrometers). According to van Veen et al. [54], the $\mathrm{D}_{2}$ gas inside the voids is expected to be released during annealing at 400-600 K (detrapping energy $\sim 1.0 \mathrm{eV}$ ), whereas the $\mathrm{D}$ atoms bound on the inner surface of voids (binding energy $\sim 1.7 \mathrm{eV}$ ) is expected to be released at $700-900 \mathrm{~K}$. Actually, the D depth profiles (Figs. 1 and 5) show that the D concentration at depths of 1-3 $\mu \mathrm{m}$ starts to decrease significantly at the exposure temperatures above $500 \mathrm{~K}$ confirming the assumption about formation of the $\mathrm{D}_{2}$-filled voids.

The depths of $\mathrm{D}$ accumulation (several micrometers) are much larger than the deuterium implantation range (several nanometers). Moreover, deuterium ions with energies less than $800 \mathrm{eV}$ are not able to produce displacement damage in tungsten [22]. A review of hydrogen bubbles in metals by Condon and Schober [55] outlines a possible mechanism of void formation - the mechanism of near-surface plastic deformation caused by the deuterium supersaturation within the near-surface layer. During D ion irradiation or D plasma exposure the D concentration in the implantation zone greatly exceeds the solubility limit and stresses the matrix lattice until plastic deformation with formation of voids and vacancy clusters occurs to alleviate these tensions. This deformation is assumed to be responsible for the sudden increase in trapping sites for deuterium and the concurrent accumulation of deuterium, both in the form of $\mathrm{D}_{2}$ molecules and $\mathrm{D}$ atoms. Traces of the plastic deformation within the sub-surface layer of the $\mathrm{W}$ single crystal are observed on the surface as etching pits (Luder's bunds) oriented along certain crystallographic plane (Fig. 7 a). These etching pits are created due to preferential sputtering of dislocation lines intersecting the surface. According to Savitsky and Burkhanov [56], at plastic deformations of $6-10 \%$ the dislocation lines in the bcc lattice are parallel to the direction of the closest packing. But at higher degree of the deformation, a texture is formed. 
It has been shown recently [39] that after irradiation with $200 \mathrm{eV}$ D ions at a low flux of about $4 \times 10^{19} \mathrm{D} / \mathrm{m}^{2} \mathrm{~s}$, the maximum concentration of deuterium (rather $\mathrm{D}_{2}$ molecules) at depths of 1-3 $\mu \mathrm{m}$ in the polycrystalline $\mathrm{W}$ specimen is at least one order of magnitude higher than that in the $\mathrm{W}$ single crystals. This suggests that the initial structure of the $\mathrm{W}$ materials plays a major role in the stress-induced void formation. Possibly, the grain boundaries serve as preferential sites for void nucleation and growth. However, after exposure to the high-flux $\left(1.1 \times 10^{21} \mathrm{D} / \mathrm{m}^{2} \mathrm{~s}\right) \mathrm{D}$ plasma, the maximum $\mathrm{D}$ concentration in the sub-surface layer (at depths of 1-3 $\mu \mathrm{m}$ ) is 0.3-0.4 at.\% both in the $\mathrm{W}$ single crystal and polycrystalline W (Fig. 1). Apparently, for high-flux D ion implantation formation of the stress-induced defect depends on the $\mathrm{W}$ structure to a lesser degree than for low-flux implantation.

In the polycrystalline $\mathrm{W}$ exposed to the carbon-seeded $\mathrm{D}$ plasma, the temperature of maximum retention of deuterium (rather in the form of $\mathrm{D}_{2}$ molecules) is shifted by $100 \mathrm{~K}$ towards higher temperatures as compared to the "clean" D plasma exposure. Additionally, for the carbon-seeded D plasma exposure the D concentration at intrinsic defects (beyond 6 $\mu \mathrm{m})$ at the exposure temperatures above $600 \mathrm{~K}$ is about one order of magnitude higher than that for the "clean" D plasma exposure. We expect that the tungsten carbide layer on tungsten surfaces formed by simultaneous deuterium and carbon implantation could prevent the implanted deuterium from leaving the tungsten [15]. As a result, the flux of deuterium atoms diffusing into the bulk increases. In doing so, the temperature of the maximum deuterium retention in the zone of the stress-induced defects is shifted from about 500 to about $600 \mathrm{~K}$ (Fig. 4 b), and the concentration of deuterium trapped at intrinsic defects at higher exposure temperatures significantly increases.

According to van Veen et al. [54], the maximum temperature at which molecular deuterium can be accumulated in voids is about $600 \mathrm{~K}$, therefore one might expect that at higher fluxes of deuterium atoms diffusing into the bulk the maximum retention at depths of 1-3 $\mu \mathrm{m}$ will be observed at about $600 \mathrm{~K}$. At that, the concentration of D atoms trapped at intrinsic defects in the bulk might be increased.

Ueda et al. [15] proposed two mechanisms to control deuterium migration through a tungsten carbide layer. One is to decrease deuterium diffusion through the tungsten carbide layer, and other is to reduce the recombination rate of deuterium atoms on the surface. Regarding the hydrogen diffusion in tungsten carbide, Atsumi et al. [57] have reported data indicating that the diffusivity of hydrogen isotopes in tungsten carbide layer is very different from that in pure W. In these experiments hydrogen absorption was measured 
under a hydrogen atmosphere of about $10 \mathrm{kPa}$. They showed that coexisting carbon with tungsten strongly suppressed hydrogen retention and diffusion in tungsten. Deuterium depth profiles in chemical vapor deposited tungsten carbides $\mathrm{W}_{2} \mathrm{C}$ and $\mathrm{WC}[58]$ and in the polycrystalline $\mathrm{W}$ exposed to the low-energy and high ion flux D plasma to the same ion fluence at temperatures below $500 \mathrm{~K}$ show that $\mathrm{D}$ atoms penetrate in the polycrystalline $\mathrm{W}$ much deeper than in tungsten carbides. Thus, these results suggest that tungsten carbide layers formed on the $\mathrm{W}$ surface during exposure to the carbon-seeded D plasmas act as a diffusion barrier to deuterium.

Concerning the recombination of hydrogen atoms on the surface, there is no reliable data so far. According to Ogorodnikova [36] and Ueda et al. [15], the presence of carbon atoms on the $\mathrm{W}$ surface, however, can reduce the recombination rate of hydrogen atoms.

Both the carbide barrier layer for $\mathrm{D}$ diffusion and the reduced recombination rates lead to the build-up of high D concentrations in the nearest-surface layer, to a larger indepth migration of deuterium, and finally to a larger probability of vacancy cluster and void formation in deeper layers. In doing so, formation of deuterium-defects complexes/voids may occur at higher exposure temperature (at about $600 \mathrm{~K}$ ) than that in the case of the $\mathrm{W}$ surface without the tungsten carbide layer (at about $500 \mathrm{~K}$ ).

Recent observation of modification of tungsten surfaces exposed to low energy and high flux plasmas and ion beam bombardment have shown the formation of blisters [22, $23,27,37,42,45,59-61]$. In our experiments at the exposure temperatures between 350 and $500 \mathrm{~K}$, in spite of the same D retention, the mean size of blisters after the carbonseeded D plasma exposure is by about one order of magnitude larger than that after the “clean" D plasma exposure. Mechanical properties of tungsten carbides (the Poisson's ratio, the shear modulus) are thought to differ from those for pure W. Possibly, these parameters are the reason for the different sizes of the blisters formed at the same temperature under exposure to the "clean" and carbon-seeded D plasmas.

There are mainly two different models which describe the blistering process. One is the gas driven model [62-64], in which bubbles are assumed to grow by coalescence or the loop punching mechanism [65]. As more deuterium is deposited and bubbles grow, cooperative fracture between the bubbles suddenly becomes an easy way of relieving their overpressure, thus initiating cracks, allowing internal gas release, and lifting the surface off the implanted material into dome-shaped blisters. Another is the lateral stress model [66, 67] in which stresses are assumed to be introduced in the implanted layer and the surface will buckle if the induced stress becomes too high. 
After exposure to the "clean" D plasma at $T_{\exp }=573 \mathrm{~K}$ to an ion fluence of $2 \times 10^{24}$ $\mathrm{D} / \mathrm{m}^{2}$, the blister size (diameter) reaches $30 \mu \mathrm{m}$ (Fig. 9), while the concentration of deuterium is relatively low (about $10^{-2}$ at.\%). This fact points to the lateral stress model to describe the blister formation mechanism.

\section{Conclusions}

Depth profiles of deuterium trapped in single-crystalline and polycrystalline $\mathrm{W}$ exposed to a low energy $(\approx 200 \mathrm{eV} / \mathrm{D})$ and high deuterium ion flux $\left(1.1 \times 10^{21} \mathrm{D} / \mathrm{m}^{2} \mathrm{~s}\right)$ in "clean" and carbon-seeded D plasmas at a fluence of about $2 \times 10^{24} \mathrm{D} / \mathrm{m}^{2}$ and temperatures from 313 to $853 \mathrm{~K}$ have been measured using the $\mathrm{D}\left({ }^{3} \mathrm{He}, \mathrm{p}\right)^{4} \mathrm{He}$ nuclear reaction, analyzing both the $\alpha$ particles and protons. To determine the $\mathrm{D}$ concentration at depths up to $7 \mu \mathrm{m}$, an analyzing beam of ${ }^{3} \mathrm{He}$ ions with energies from 0.69 to $4.0 \mathrm{MeV}$ was used.

In the case of the "clean" D plasma exposure, the total deuterium retention in singlecrystalline and polycrystalline $\mathrm{W}$ increases with the exposure temperature, reaching its maximum value of $5 \times 10^{20} \mathrm{D} / \mathrm{m}^{2}$ at about $500 \mathrm{~K}$, and then decreases as the temperature grows further. Seeding of carbon into the D plasma does not significantly change the maximum $\mathrm{D}$ retention in the polycrystalline $\mathrm{W}$, but shifts the temperature at which the $\mathrm{D}$ retention peaks are at maximum, to about $600 \mathrm{~K}$. The high $\mathrm{D}$ concentration (about 0.3 at.\%) at depths of 1-3 $\mu \mathrm{m}$, observed after exposure to the "clean" and carbon-seeded D plasma at temperatures of the maximum $\mathrm{D}$ retention, is due to accumulation of $\mathrm{D}_{2}$ molecules in voids created during D plasma exposure. At exposure temperatures above $600 \mathrm{~K}$ deuterium is retained in the polycrystalline $\mathrm{W}$ as $\mathrm{D}$ atoms chemisorbed at the walls of microvoids initially presented in the hot-rolled powder-metallurgy $\mathrm{W}$ matrix.

It can be assumed that tungsten carbide is formed on the $\mathrm{W}$ surface under exposure to the carbon-seeded D plasmas, it serves as a barrier layer for diffusion and prevents the outward transport of deuterium, thus increasing the $\mathrm{D}$ retention in the bulk of polycrystalline $\mathrm{W}$ matrix.

D plasma exposure with ion energies well below the displacement threshold modifies the $\mathrm{W}$ structure to depths of up to about $5 \mu \mathrm{m}$, both in $\mathrm{W}$ single crystals and polycrystalline W. Plastic deformation of the W surface caused by deuterium super-saturation within the near-surface layer is suggested as a mechanism for $\mathrm{D}_{2}$-filled void formation.

\section{Acknowledgements}


We express our appreciation to J. Dorner and M. Fußeder (IPP Garching) for their technical assistance with the ${ }^{3} \mathrm{He}$ beam analyses. One of us, V. Alimov, gratefully acknowledges financial support from the Max-Planck-Institut für Plasmaphysik and is candidly indebted to his colleagues from the Materialforschung Division for their warm hospitality during his stay in Garching. The portion of this work performed in Moscow was supported by the US Department of Energy under Contract 155638 with Sandia National Laboratories and International Scientific and Technical Centre under Project \#2805.

\section{References}

[1] G. Federici, P. Andrew, P. Barabaschi, J. Brooks, R. Doerner, A. Geier, A. Herrmann, G. Janeschitz, K. Krieger, A. Kukushkin, A. Loarte, R. Neu, G. Saibene, M. Shimada, G. Strohmayer, and M. Sugihara, J. Nucl. Mater. 313-316 (2003) 11.

[2] D. Naujoks, W. Eckstein, J. Nucl. Mater. 220-222 (1995) 993.

[3] D. Naujoks, W. Eckstein, J. Nucl. Mater. 230 (1996) 93.

[3] D. Hildebrandt, P. Wienhold, W. Schneider, J. Nucl. Mater. 290-293 (2001) 89.

[4] R. Kawakami, K. Ohya, J. Nucl. Mater. 313-316 (2003) 107.

[5] R. Kawakami, T. Shimada, Y. Ueda, M. Mishikawa, J. Nucl. Mater. 329-333 (2004) 737.

[6] T. Mitani, R. Kawakami, S. Kuriu, J. Nucl. Mater. 329-333 (2004) 830.

[7] R. Kawakami, T. Mitani, J. Nucl. Mater. 337-339 (2005) 45.

[8] R. Kawakami, J. Nucl. Mater. 348 (2006) 256.

[9] J. Luthin, Ch. Linsmeier, Surf. Sci. 454-456 (2000) 78.

[10] J. Luthin, Ch. Linsmeier, J. Nucl. Mater. 290-293 (2001) 121.

[11] T. Shimada, Y. Ueda, M. Nishikawa, Fusion Eng. Design 66-68 (2003) 247.

[12] T. Shimada, T. Funabiki, R. Kawakami, Y. Ueda, M. Nishikawa, J. Nucl. Mater. 329333 (2004) 747.

[13] Y.Ueda, M. Fukumoto, I. Sawamura, D. Sakizono, T. Shimada, M. Nishikawa, Fusion Eng. Design 81 (2006) 233.

[14] Y. Ueda, H. Kikuchi, T. Shimada, A. Sagara, B. Kyoh, M. Nishikawa, Fusion Eng. Design 61\&62 (2002) 255.

[15] Y. Ueda, T. Shimada, M. Nishikawa, Nucl. Fusion 44 (2004) 62.

[16] T. Shimada, H. Kikuchi, Y. Ueda, A. Sagara, M. Nishikawa, J. Nucl. Mater. 313-316 (2003) 204. 
[17] R.A. Anderl, D.F. Holland, G.R. Longhurst, R.J. Pawelko, C.L. Trybus, C.H. Sellers, Fusion Technol. 21 (1992) 745.

[18] R. Sakamoto, T. Muroga, N. Yoshida, J. Nucl. Mater. 220-222 (1995) 819.

[19] V.Kh. Alimov, B.M.U. Scherzer, J. Nucl. Mater. 240 (1996) 75.

[20] A.A. Haasz, J.W. Davis, M. Poon, R.G. Macaulay-Newcombe, J. Nucl. Mater. 258263 (1998) 889.

[21] R. Causey, K. Wilson, T. Venhaus, W.R. Wampler, J. Nucl. Mater. 266-269 (1999) 467.

[22] A.A. Haasz, M. Poon, J.W. Davis, J. Nucl. Mater. 266-269 (1999) 520.

[23] F.C. Sze, L. Chousal, R.P. Doerner, S. Luckhardt, J. Nucl. Mater. 266-269 (1999) 1212.

[24] S. Nagata, K. Takahiro, S. Horiike, S. Yamaguchi, J. Nucl. Mater. 266-269 (1999) 1151.

[25] S. Nagata, K. Takahiro, J. Nucl. Mater. 283-287 (2000) 1038.

[26] A.A. Haasz, M. Poon, R.G. Macaulay-Newcombe, J.W. Davis, J. Nucl. Mater. 290$293(2001) 85$.

[27] T. Venhaus, R. Causey, R. Doerner, T. Abeln, J. Nucl. Mater. 290-293 (2001) 505.

[28] V.Kh. Alimov, K. Ertl, J. Roth, J. Nucl. Mater. 290-293 (2001) 389.

[29] V.Kh. Alimov, K. Ertl, J. Roth, K. Schmid, Physica Scripta T94 (2001) 34.

[30] V.Kh. Alimov, A.P. Zakharov, R.Kh. Zalavutdinov, in: A. Hassanein (Ed.), Hydrogen and Helium Recycling at Plasma Facing Materials, NATO Science Series II, vol. 54, Kluwer Academic, 2002, p. 131.

[31] R.G. Macaulay-Newcombe, A.A Haasz, M. Poon, J.W. Davis, in: A. Hassanein (Ed.), Hydrogen and Helium Recycling at Plasma Facing Materials, NATO Science Series II, vol. 54, Kluwer Academic, 2002, p. 145.

[32] M. Poon, R.G. Macaulay-Newcombe, J.W. Davis, A.A. Haasz, J. Nucl. Mater. 307$311(2002) 723$.

[33] B.M. Oliver, T.J. Venhaus, R.A. Causey, F.A. Garner, S.A. Maloy, J. Nucl. Mater. 307-311 (2002) 1418.

[34] H. Iwakiri, K. Morishita, N. Yoshida, J. Nucl. Mater. 307-311 (2002) 135.

[35] M. Poon, A.A. Haasz, J.W. Davis, R.G. Macaulay-Newcombe, J. Nucl. Mater. 313$316(2003) 199$.

[36] O.V. Ogorodnikova, J. Roth, M. Mayer, J. Nucl. Mater. 313-316 (2003) 469.

[37] W. Wang, J. Roth, S. Lindig, C.H. Wu, J. Nucl. Mater. 299 (2001) 124.

[38] V.Kh. Alimov, Physica Scripta T 108 (2004) 46. 
[39] V.Kh. Alimov, J. Roth, M. Mayer, J. Nucl. Mater. 337-339 (2005) 619.

[40] B.M. Oliver, R.A. Causey, S.A. Maloy, J. Nucl. Mater. 329-333 (2005) 977.

[41] D. Nishijima, T. Sugimoto, H. Iwakiri, M.Y. Ye, N. Ohno, N. Yoshida, S. Takamura, J. Nucl. Mater. 337-339 (2005) 927.

[42] K. Tokunaga, M.J. Baldwin, R.P. Doerner, N. Noda, Y. Kubota, N. Yoshida,

T. Sogabe, T. Kato, B. Schedler, J. Nucl. Mater. 337-339 (2005) 887.

[43] M. Poon, R.G. Macaulay-Newcombe, J.W. Davis, A.A. Haasz, J. Nucl. Mater. 337$339(2005) 629$.

[44] K. Katayama, T. Kawasaki, Y. Manabe, H. Nagase, T. Takeishi, M. Nishikawa, Thin Solid Films 506-507 (2006) 188.

[45] G.-N. Luo, W.M. Shu, M. Nishi, Fusion Eng. Design 81 (2006) 957.

[46] V.Kh. Alimov, K. Ertl, J. Roth, K. Schmid, J. Nucl. Mater. 282 (2000) 125.

[47] M. Poon, J.W. Davis, A.A. Haasz, J. Nucl. Mater. 283-287 (2000) 1062.

[48] M. Mayer, SIMNRA User's Guide, Tech. Rep. IPP 9/113, Garching, 1997, and www.rzg.mpg.de/ mam.

[49] V.Kh. Alimov, M. Mayer, J. Roth, Nucl. Instr. and Meth. B 234 (2005) 169.

[50] J. Luthin, Chemical Interaction During the Formation Carbon-Based Mixed Materials, Ph.D. Thesis, Max-Planck-Institut für Plasmaphysik, IPP Report 9/129, 2001 (in German).

[51] MultiPak, Ver. 7.0.1, Physical Electronics (2004).

[52] D.A. Shirley, Phys. Rev. B 5 (1972) 4709.

[53] J. Luthin, H. Plank, J. Roth, Ch. Linsmeier, Nucl. Instr. and Meth. B 182 (2001) 218.

[54] A. van Veen, J. de Vries, D. Segers, and G.J. Rozing, in: P.C. Jain, R.M. Singru and K.P. Gopinathan (Eds.), Positron Annihilation, World Scientific Publ. Co., Singapore, 1985, p. 543.

[55] J.B. Condon and T. Schober, J. Nucl. Mater. 207 (1993) 1.

[56] E.M. Savitsky, G.S.Burkhanov, Single Crystals of Refractory and Less-Common Metals and Alloys, Nauka, Moscow, 1972 (in Russian).

[57] H. Atsumi, T. Tanabe, J. Nucl. Mater. 258-263 (1998) 896.

[58] V.Kh. Alimov and J. Roth, Private communication (2007).

[59] F.C. Sze, R.P. Doerner, S. Luckhardt, J. Nucl. Nater. 264 (1999) 89.

[60] M.Y. Ye, H. Kanehara, S. Fukuda, N. Ohno, S. Takamura, J. Nucl. Nater. 313-316 (2003) 72.

[61] G.-N. Luo, W.M. Shu, M. Nishi, J. Nucl. Mater. 347 (2005) 111-117.

[62] J.H. Evans, J. Nucl. Mater. $76 \& 77$ (1978) 228. 
[63] S.K. Das, M. Kaminsky, G. Fenske, J. Nucl. Mater. 76\&77 (1978) 215.

[64] S.K. Das, M. Kaminsky, G. Fenske, J. Appl. Phys. 50 (1979) 3304.

[65] G.W. Greenwood, A.J.E. Foreman, D.E. Rimmer, J. Nucl. Mater. 4 (1959) 305.

[66] J. Roth, in: Applications of Ion Beams to Materials, eds. G. Carter, J.S. Colligan, N.A. Grant (The Institute of Physics, London 1976) p. 280.

[67] E.P. EerNisse, S.T. Picraux, J. Appl. Phys. 48 (1977) 9. 

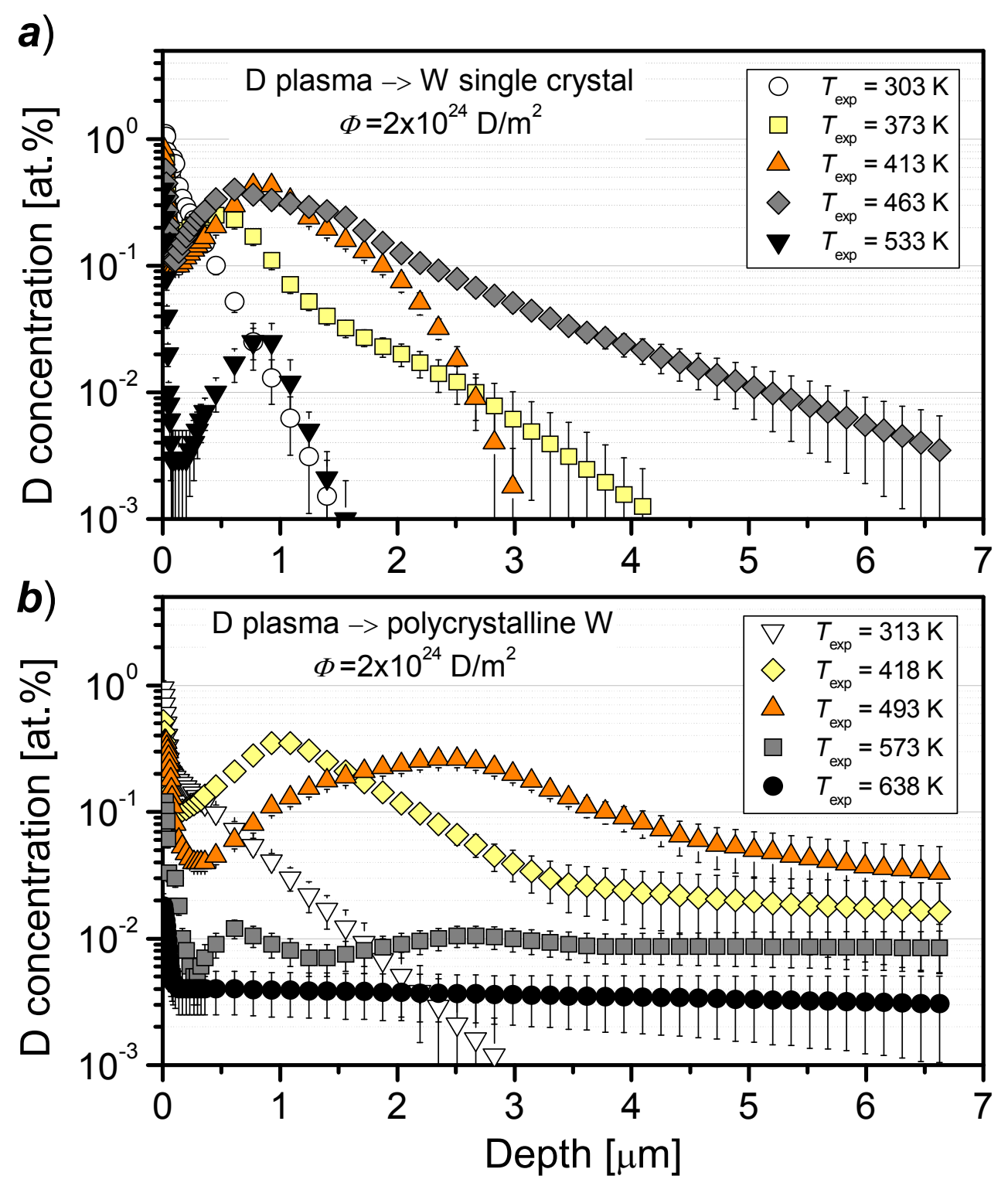

Fig. 1. Depth profiles of deuterium trapped in $\mathrm{W}$ single crystal (a) and polycrystalline W (b) exposed to a low-energy ( $\approx 200 \mathrm{eV} / \mathrm{D})$ and high ion flux $\left(1.1 \times 10^{21} \mathrm{~m}^{-2} \mathrm{~s}^{-1}\right)$ "clean" deuterium plasma to an ion fluence of $2 \times 10^{24} \mathrm{D} / \mathrm{m}^{2}$ at various temperatures. 


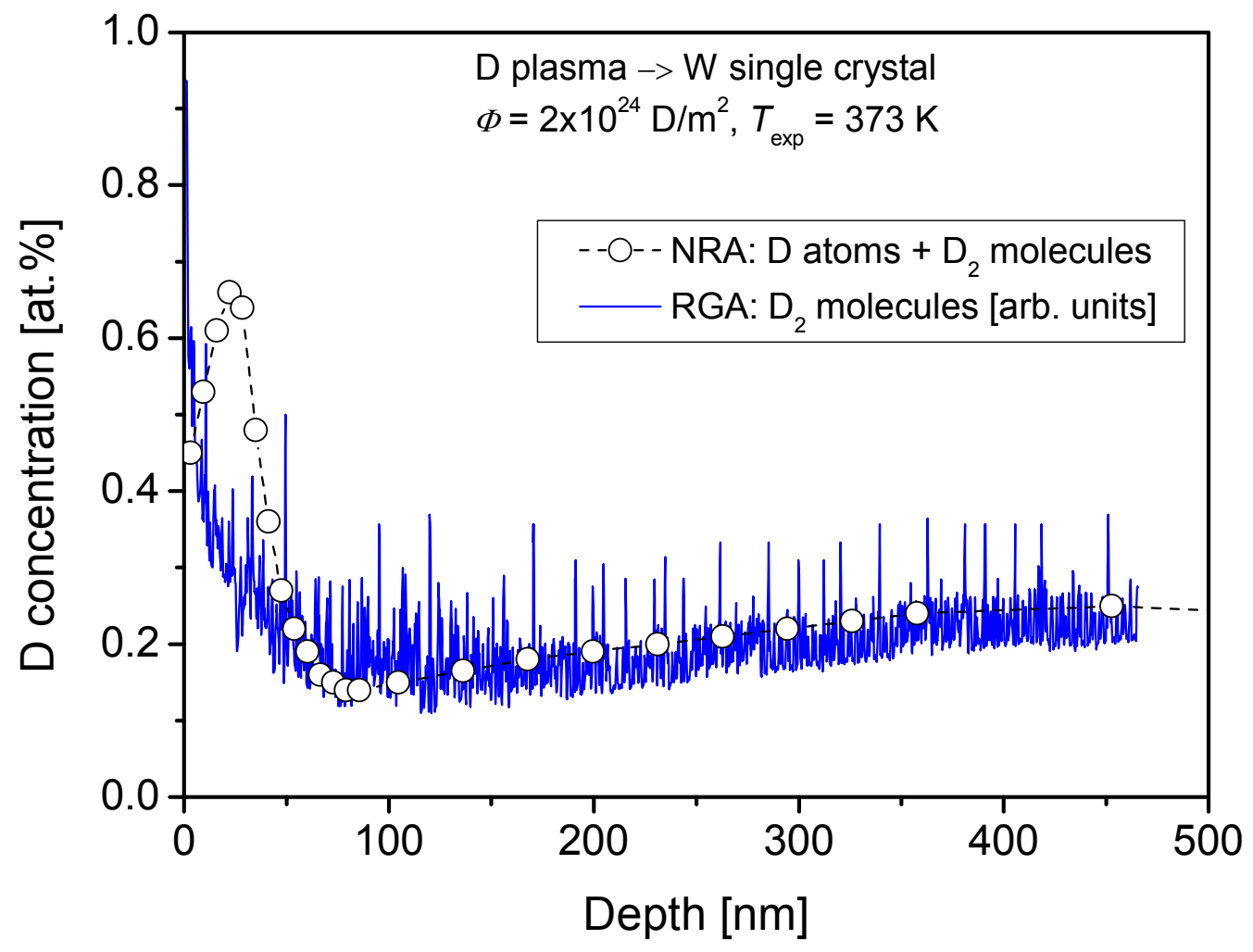

Fig. 2. Depth profile of deuterium in $\mathrm{W}$ single crystal exposed to a low-energy $(\approx 200$ $\mathrm{eV} / \mathrm{D})$ and high ion flux $\left(1.1 \times 10^{21} \mathrm{~m}^{-2} \mathrm{~s}^{-1}\right)$ "clean" deuterium plasma to an ion fluence of $2 \times 10^{24} \mathrm{D} / \mathrm{m}^{2}$ at $373 \mathrm{~K}$ as measured with the $\mathrm{D}\left({ }^{3} \mathrm{He}, \alpha\right) \mathrm{H}$ nuclear reaction (NRA) and with the sputter-residual gas analysis technique (RGA). Note that the concentration of $\mathrm{D}_{2}$ molecules (RGA measurement) is given in arbitrary units. 


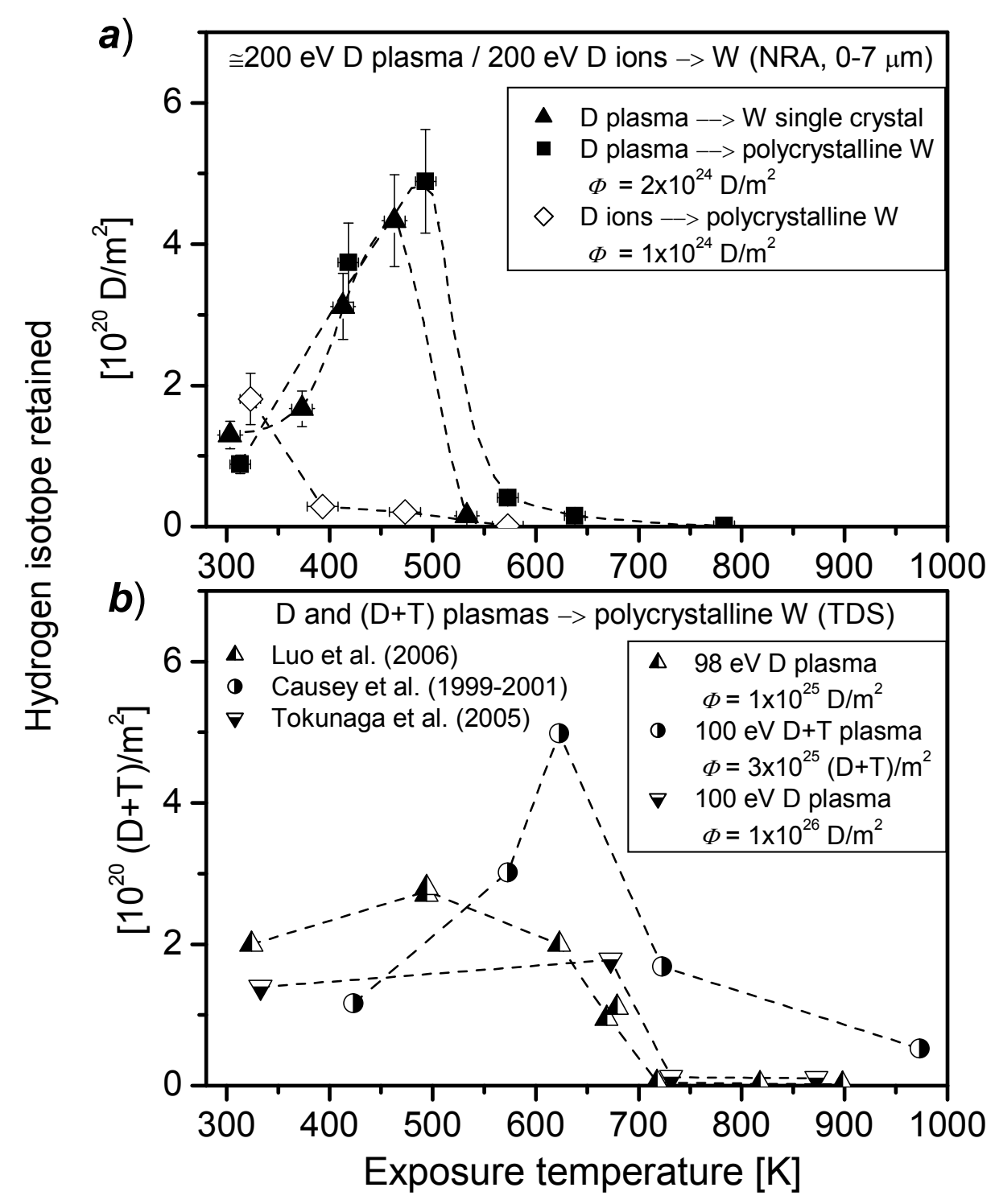

Fig. 3. a) Deuterium retention in single-crystalline and polycrystalline tungsten exposed to a low-energy $(\approx 200 \mathrm{eV} / \mathrm{D})$ and high ion flux $\left(1.1 \times 10^{21} \mathrm{~m}^{-2} \mathrm{~s}^{-1}\right)$ "clean" deuterium plasma to an ion fluence of $2 \times 10^{24} \mathrm{D} / \mathrm{m}^{2}$ as a function of the exposure temperature. For comparison, the temperature dependence of the $\mathrm{D}$ retention in polycrystalline $\mathrm{W}$ irradiated with $200 \mathrm{eV}$ D ions and flux of $4 \times 10^{19} \mathrm{D} / \mathrm{m}^{2}$ s to a fluence of $1 \times 10^{24} \mathrm{D} / \mathrm{m}^{2}$ is also shown. The deuterium retention was calculated from deuterium depth profiles measured up to a depth of $7 \mu \mathrm{m}$.

b) Deuterium retention in polycrystalline tungsten exposed to low-energy (98-100 $\mathrm{eV} / \mathrm{D}(\mathrm{T}))$ and high ion flux $\left((0.9-1) \times 10^{22} \mathrm{~m}^{-2} \mathrm{~s}^{-1}\right)$ "clean" $\mathrm{D}$ or $(\mathrm{D}+\mathrm{T})$ plasmas as a function of the exposure temperature $[21,27,42,45]$. The D retention was examined by TDS. 


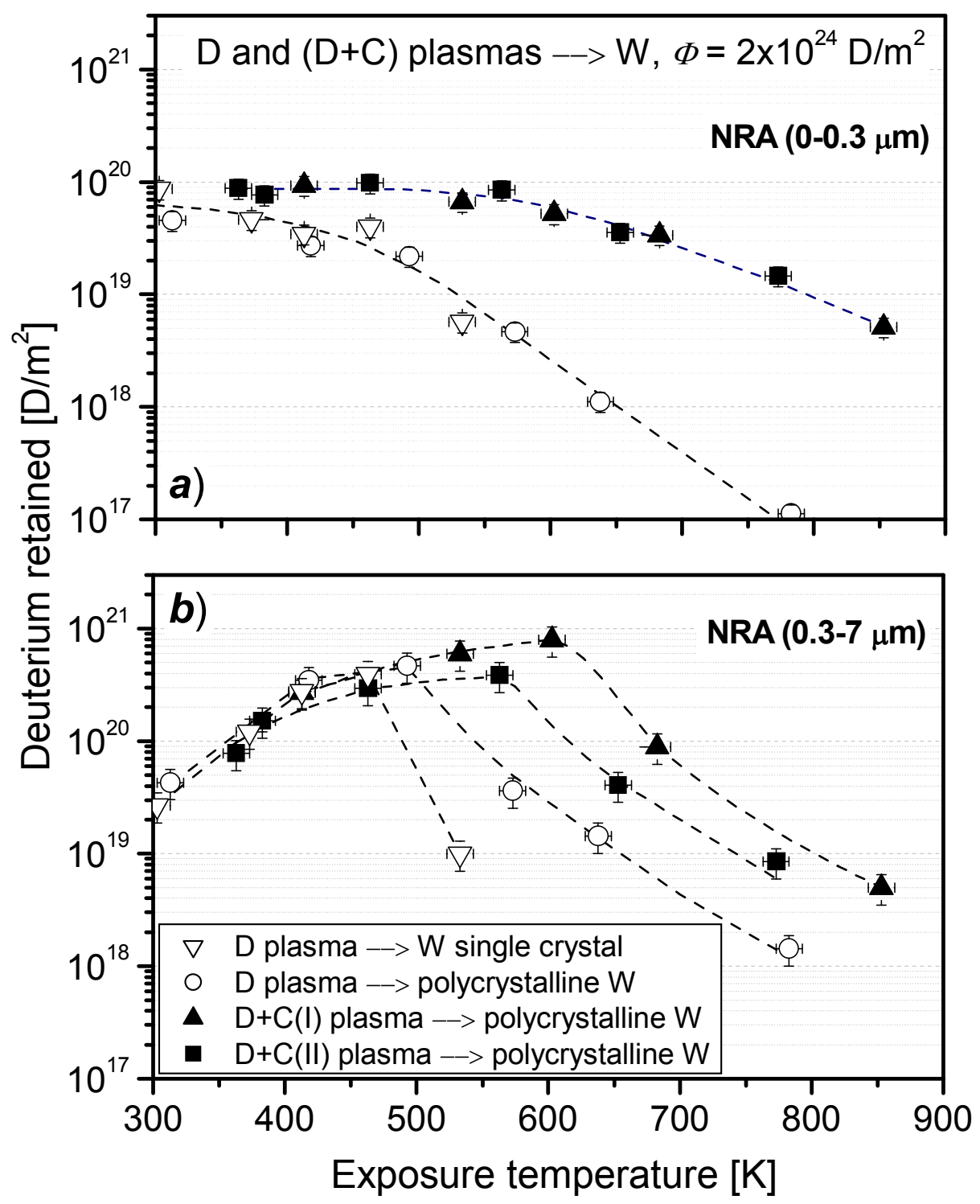

Fig. 4. Deuterium retention at depths of 0-0.3 $\mu \mathrm{m}$ (a) and at depths of $0.3-7 \mu \mathrm{m}$ (b) in single-crystalline and polycrystalline tungsten exposed to a low-energy ( $\approx 200 \mathrm{eV} / \mathrm{D})$ and high ion flux $\left(1.1 \times 10^{21} \mathrm{~m}^{-2} \mathrm{~s}^{-1}\right)$ "clean" and carbon-seeded deuterium plasmas to an ion fluence of $2 \times 10^{24} \mathrm{D} / \mathrm{m}^{2}$ as a function of the exposure temperature. 

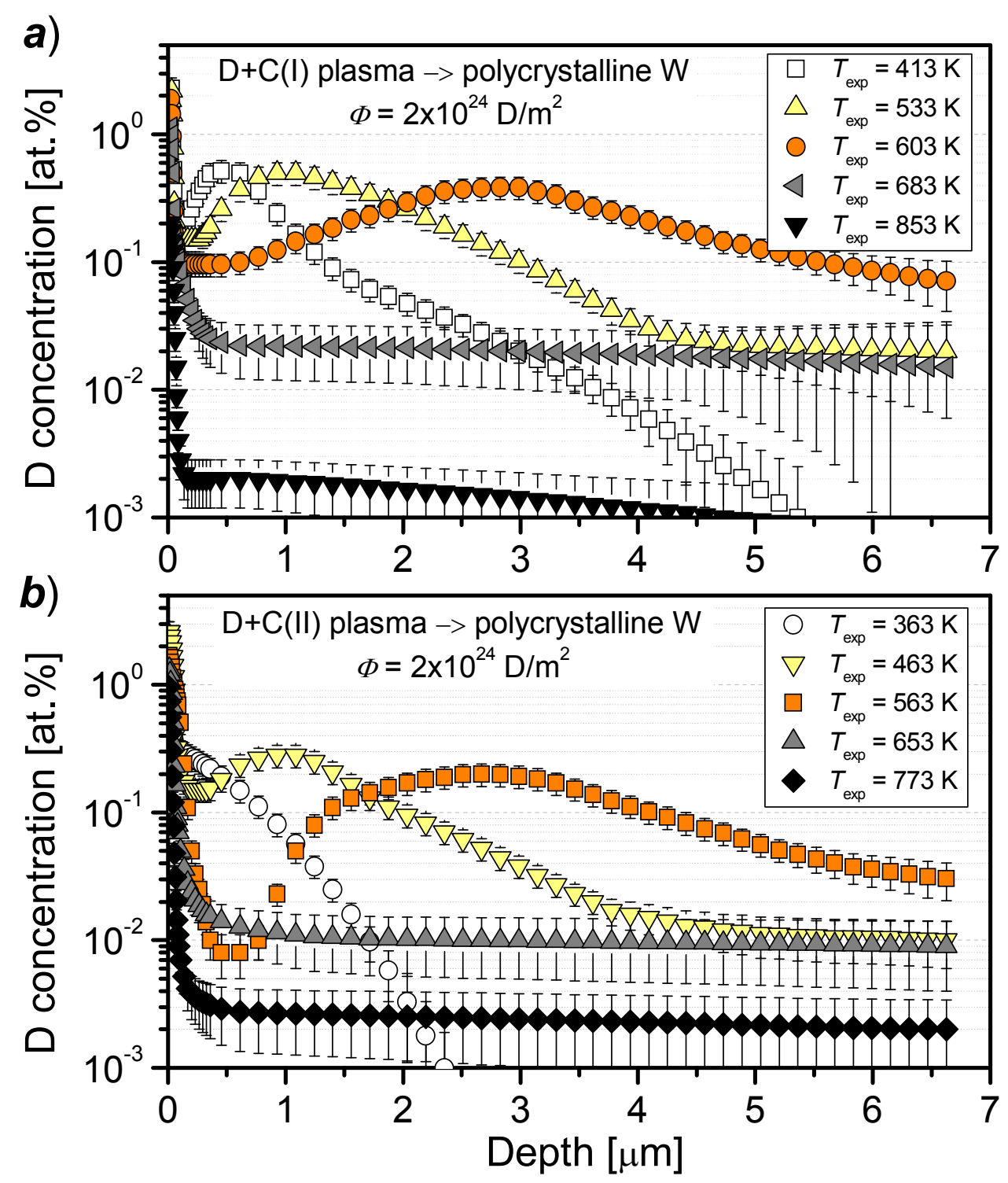

Fig. 5. Depth profiles of deuterium trapped in polycrystalline $\mathrm{W}$ exposed to a low-energy $(\approx 200 \mathrm{eV} / \mathrm{D})$ and high ion flux $\left(1.1 \times 10^{21} \mathrm{~m}^{-2} \mathrm{~s}^{-1}\right)$ carbon-seeded deuterium plasmas to an ion fluence of $2 \times 10^{24} \mathrm{D} / \mathrm{m}^{2}$ at various temperatures. 

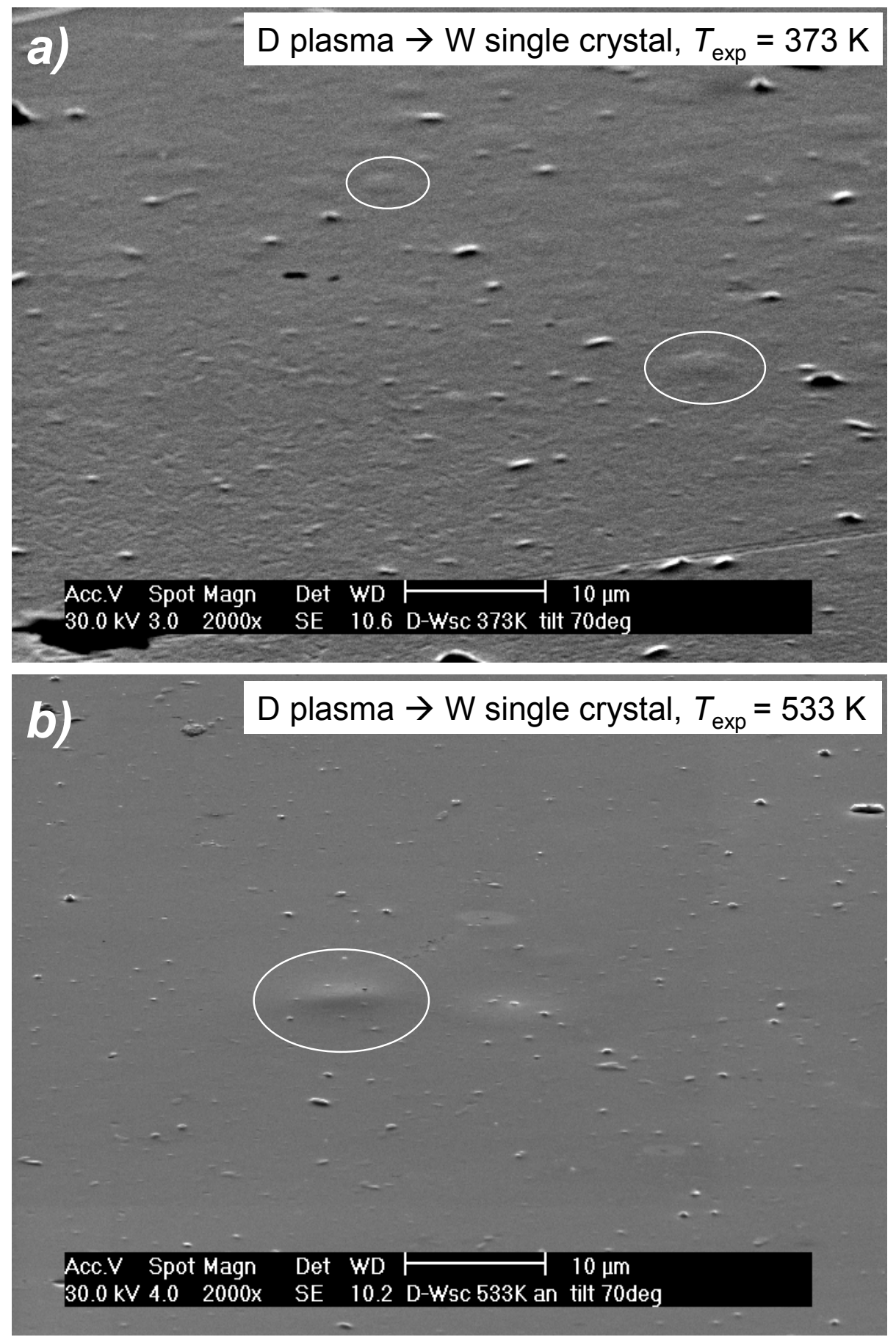

Fig. 6. Blisters formed on the surface of single-crystalline $\mathrm{W}$ exposed to a low-energy $(\approx 200 \mathrm{eV} / \mathrm{D})$ and high ion flux $\left(1.1 \times 10^{21} \mathrm{~m}^{-2} \mathrm{~s}^{-1}\right)$ "clean" deuterium plasma to an ion fluence of $2 \times 10^{24} \mathrm{D} / \mathrm{m}^{2}$ at temperatures of $373 \mathrm{~K}$ (a) and $533 \mathrm{~K}$ (b). The surfaces were analyzed at a tilt angle of 70 degrees. Some of the blisters are marked by ovals. 

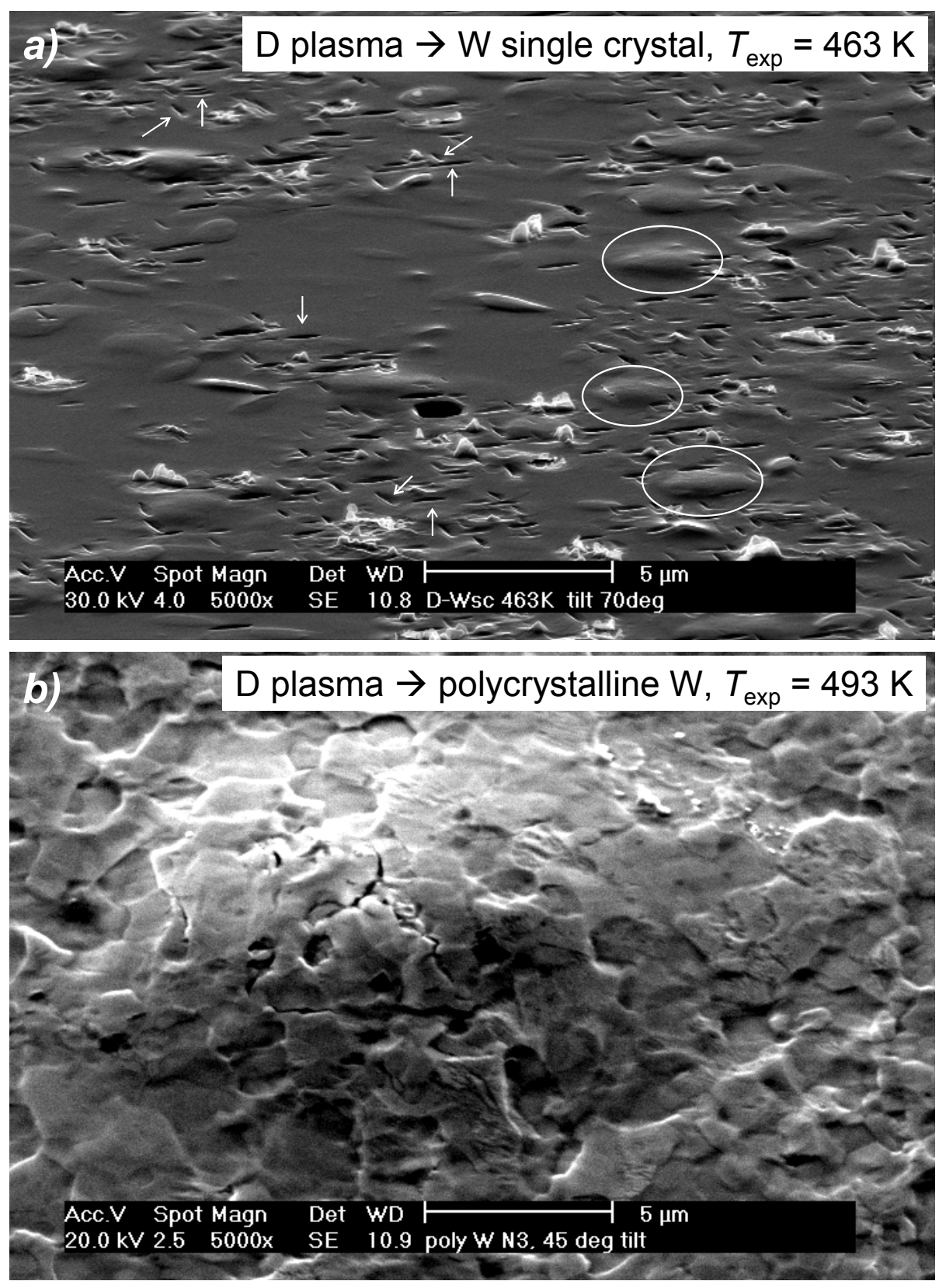

Fig. 7. SEM micrographs of $\mathrm{W}$ single crystal (a) and polycrystalline $\mathrm{W}$ (b) exposed to a low-energy $(\approx 200 \mathrm{eV} / \mathrm{D})$ and high ion flux $\left(1.1 \times 10^{21} \mathrm{~m}^{-2} \mathrm{~s}^{-1}\right)$ "clean" D plasma to a fluence of about $2 \times 10^{24} \mathrm{D} / \mathrm{m}^{2}$ at $463 \mathrm{~K}$ (a) and $493 \mathrm{~K}$ (b). The surfaces were analyzed at tilt angles of 70 (a) and 45 (b) degrees. Some of the blisters on the surface of W single crystal (a) are marked by ovals, some of the etching pits are indicated by arrows. 

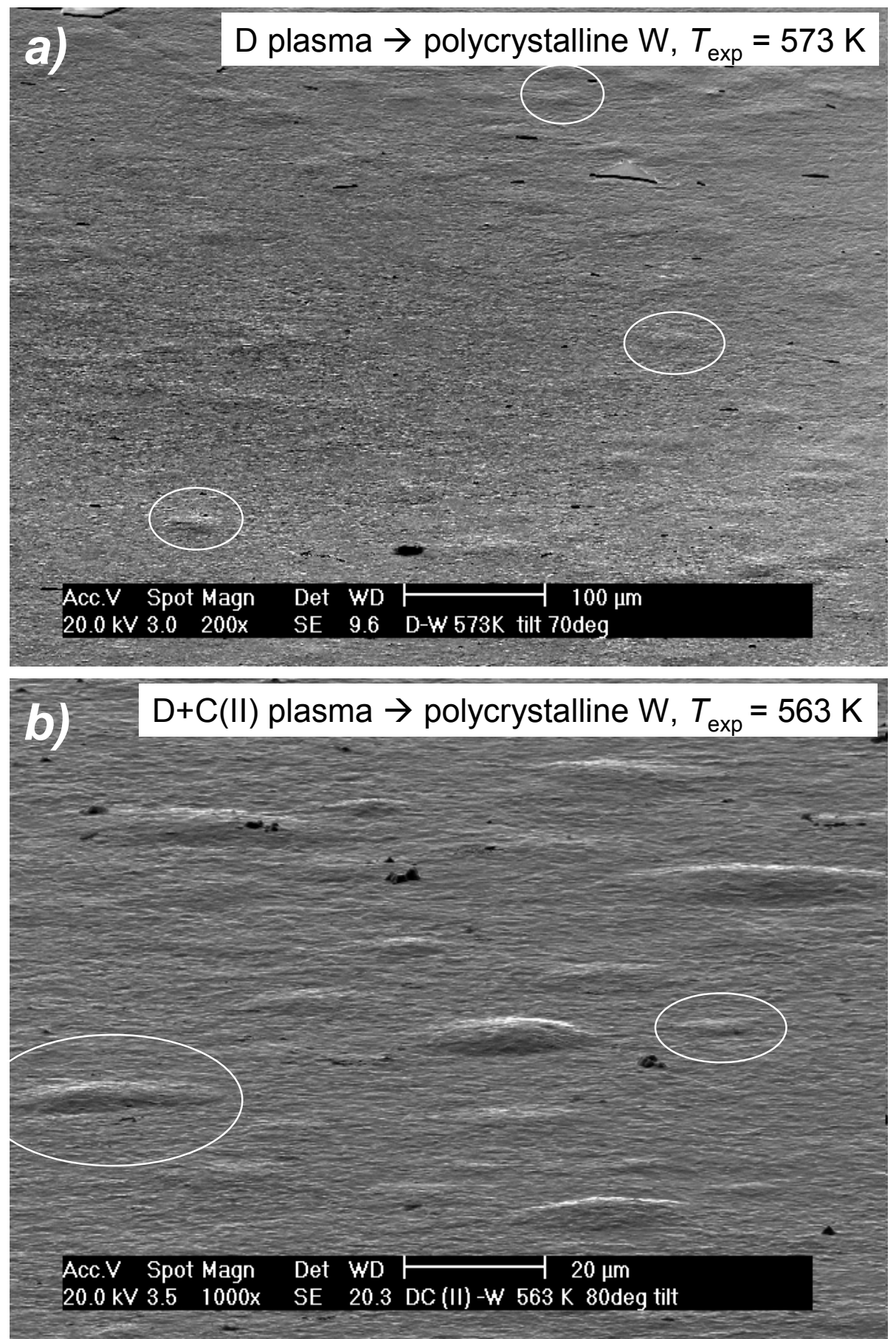

Fig. 8. Blisters formed on the surface of polycrystalline W exposed to a low-energy $(\approx 200$ eV/D) and high ion flux $\left(1.1 \times 10^{21} \mathrm{~m}^{-2} \mathrm{~s}^{-1}\right)$ "clean" (a) and carbon seeded (b) D plasmas at $T_{\exp }=563-573 \mathrm{~K}$ to an ion fluence of $2 \times 10^{24} \mathrm{D} / \mathrm{m}^{2}$. The surfaces were analyzed at tilt angles of 70 (a) and 80 (b) degrees. Some of the blisters are marked by ovals. 


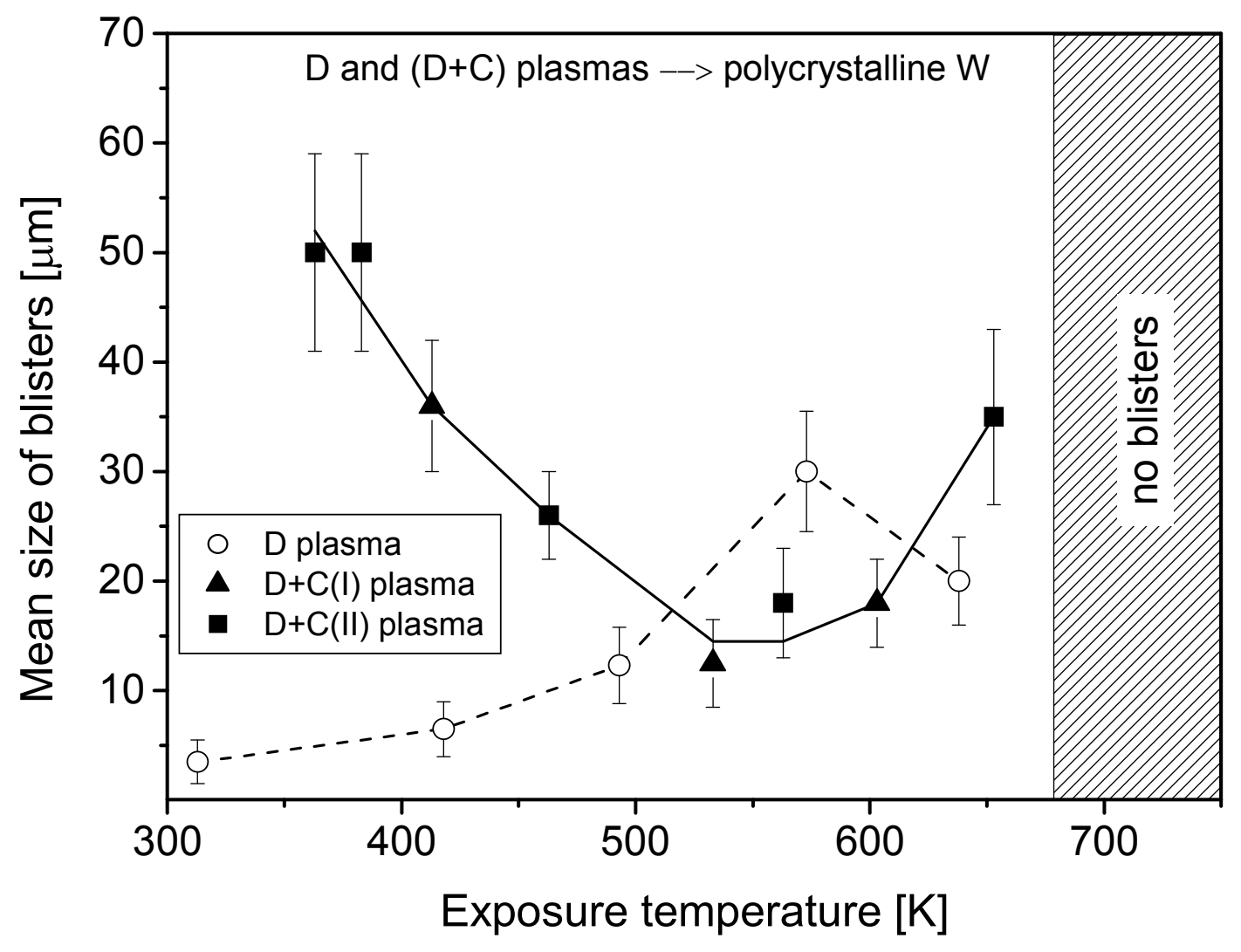

Fig. 9. Mean size (diameter) of blisters formed on the surface of polycrystalline $\mathrm{W}$ exposed to a low-energy $(\approx 200 \mathrm{eV} / \mathrm{D})$ and high ion flux $\left(1.1 \times 10^{21} \mathrm{~m}^{-2} \mathrm{~s}^{-1}\right)$ "clean" and carbonseeded D plasmas to an ion fluence of $2 \times 10^{24} \mathrm{D} / \mathrm{m}^{2}$, as a function of the exposure temperature. 


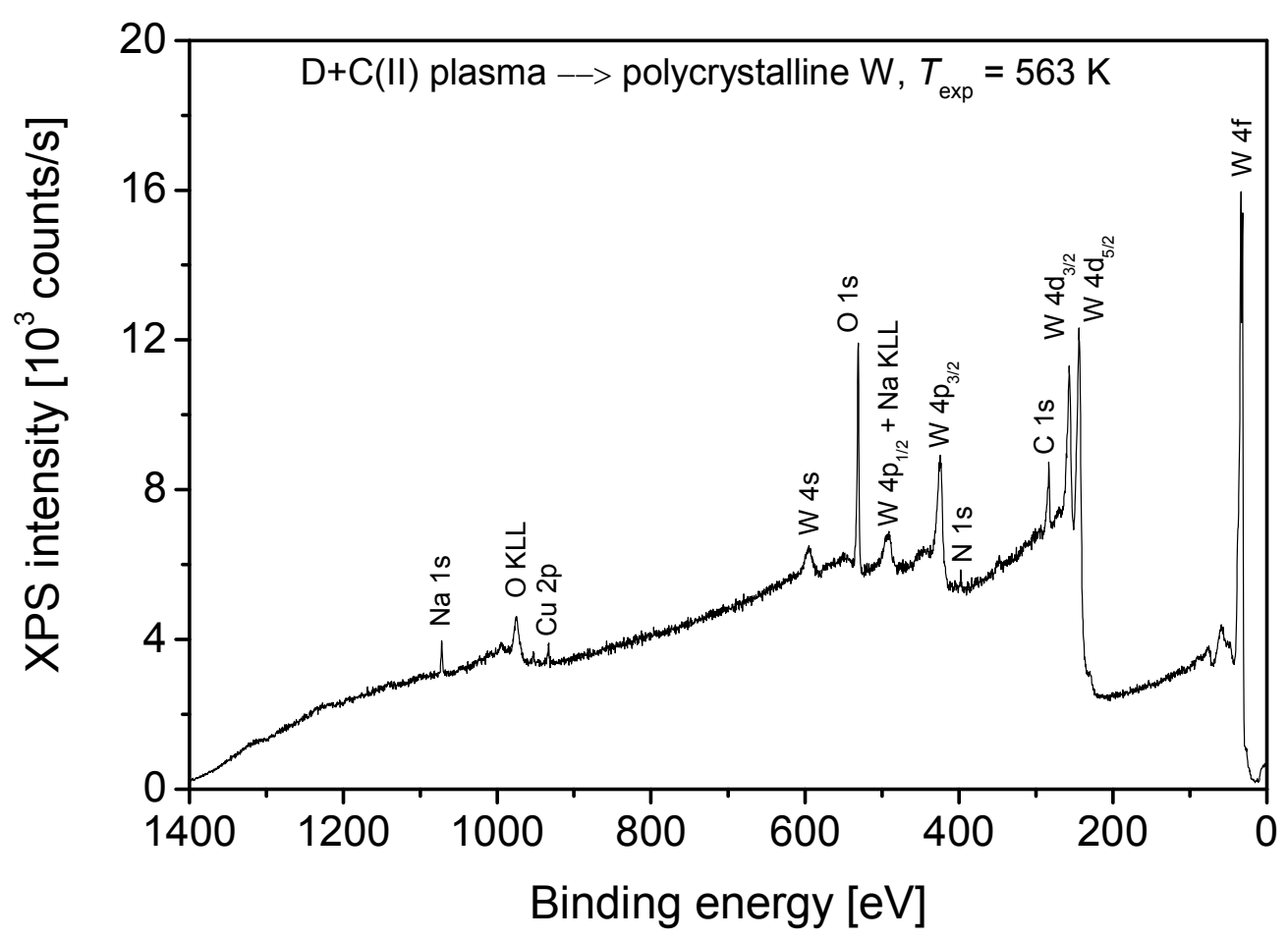

Fig 10. Survey XPS spectrum of polycrystalline W exposed to a low-energy ( $\approx 200 \mathrm{eV} / \mathrm{D})$ and high ion flux $\left(1.1 \times 10^{21} \mathrm{~m}^{-2} \mathrm{~s}^{-1}\right)$ "D $\mathrm{D}$ (II)" plasma at $T_{\exp }=563 \mathrm{~K}$ to an ion fluence of $2 \times 10^{24} \mathrm{D} / \mathrm{m}^{2}$. The XPS measurement was performed after surface sputtering with $3 \mathrm{keV} \mathrm{Ar}$ ions at a fluence of $1 \times 10^{19} \mathrm{Ar} / \mathrm{m}^{2}$. 


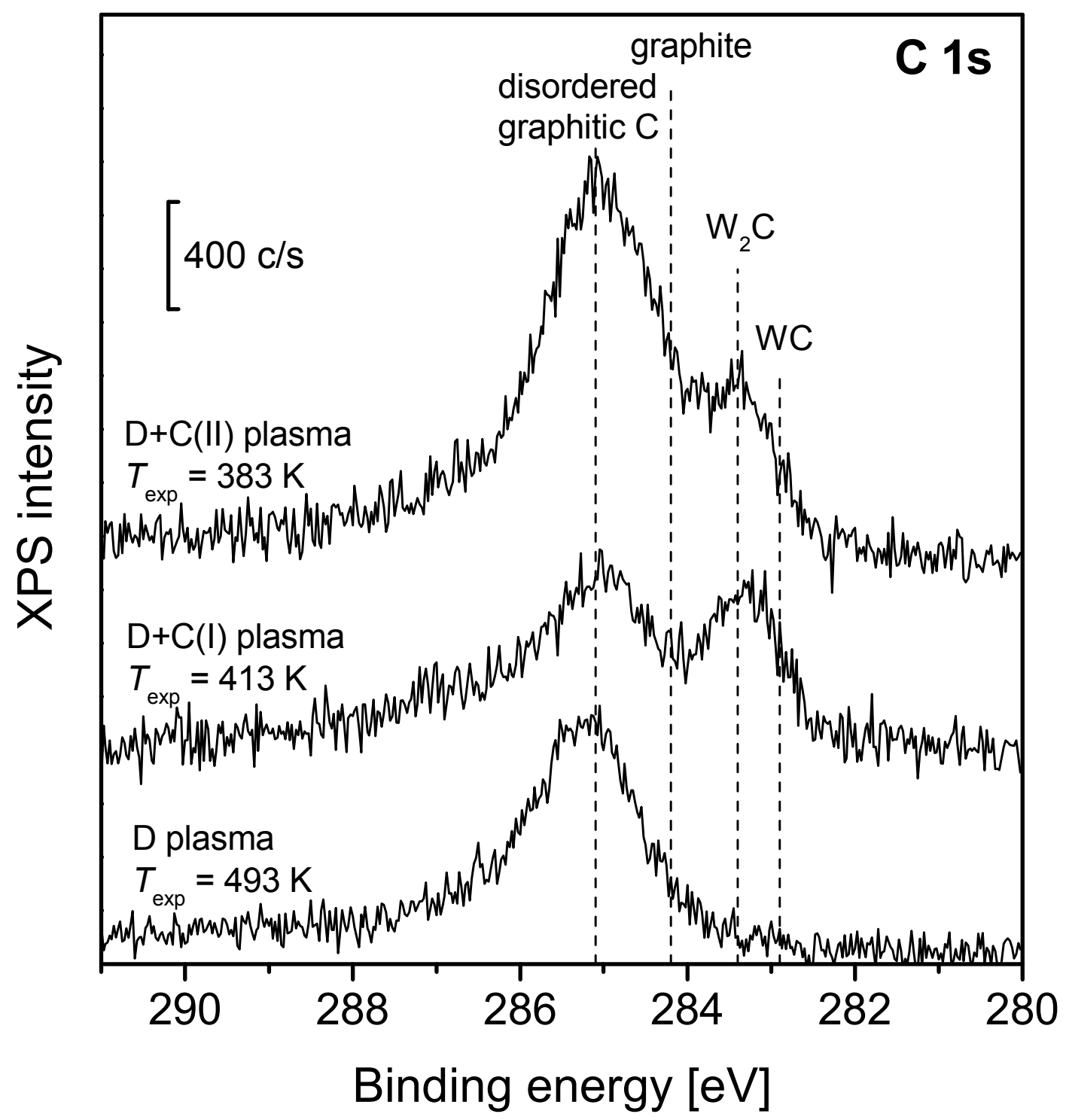

Fig. 11. C 1s core-level XPS spectra of polycrystalline tungsten exposed to a low-energy $(\approx 200 \mathrm{eV} / \mathrm{D})$ and high ion flux $\left(1.1 \times 10^{21} \mathrm{~m}^{-2} \mathrm{~s}^{-1}\right)$ "clean" and carbon-seeded D plasmas to an ion fluence of $2 \times 10^{24} \mathrm{D} / \mathrm{m}^{2}$. The XPS measurements were performed after surface sputtering with $3 \mathrm{keV}$ Ar ions at a fluence of $1 \times 10^{19} \mathrm{Ar} / \mathrm{m}^{2}$. 